\title{
Effect of Exposure to Lead Acetate on Neurobehavior and Learning in the Kitten
}

Chad T Andicochea ${ }^{1,2 *}$, Ashley K Ramsey ${ }^{3}$ and John R Martin ${ }^{1,4}$

${ }^{1}$ Department of Pharmacology, AT Still University, Kirksville College of Osteopathic Medicine, Kirksville, USA

${ }^{2}$ Department of Emergency Medicine, Naval Medical Center, Camp Lejeune, USA

${ }^{3}$ Department of Psychology, Truman State University, Kirksville, USA

${ }^{4}$ Department of Integrative Physiology and Pharmacology, Liberty University College of Osteopathic Medicine, Lynchburg, USA

\begin{abstract}
Objective: Elevated aggression and poor intelligence scores occur in children with BLLs (Blood Lead Levels) lower than $10 \mu \mathrm{g} / \mathrm{dL}$ while $\mathrm{Pb}$-exposed cats show increased aggressive behavior with BLLs of $10 \mu \mathrm{g} / \mathrm{dL}$. This increased aggression in cats may be associated with the development of hyper-spiny neurons observed in the motor cortex, hippocampus and cerebellum of kittens with BLLs $<1.2 \mu \mathrm{g} / \mathrm{dL}$. These results suggest that lead ingestion by kittens might result in learning and behavioral deficits similar to those observed in lead-burdened children.
\end{abstract}

Methods: To test this, kittens were treated $(20 \mathrm{mg} / \mathrm{kg} / \mathrm{day}$, lead acetate or distil water via esophageal intubation) from Postnatal Day (PND) 1 to 7 . At 8 and 10 weeks of age, the kittens were tested in a reversal T-maze, an openfield, and a free-fall test.

Results: 8 weeks old Pb-treated kittens showed a delay in learning as demonstrated by a significant higher number of Incorrect Arm Choices (IACs) in the T-maze that returned to control levels in 10 weeks old kittens. No differences occurred between the two groups at 8 and 10 weeks of age in the open-field or free-fall tests.

Conclusion: The impairment in the reversal T-maze suggests a $\mathrm{Pb}$-induced delay in learning, which compares favourably with current understanding of delayed learning in Pb-poisoned children.

Keywords: Spatial reversal learning; T-maze; Free-fall, Locomotion; Open-field; $\mathrm{Pb}$; Cat; Kitten

\section{Introduction}

Lead $(\mathrm{Pb})$ contamination in humans has a number of significant neurological effects. Children are more sensitive to toxic $\mathrm{Pb}$ effects, whether through acute or chronic exposure, due to their high rate of bone development, and rapid neural differentiation [1]. Results from clinical studies indicate that children with Blood Lead Levels (BLLs) of $10 \mu \mathrm{g} / \mathrm{dL}$ or greater have marked behavioral, neurological, and intellectual impairments. In addition, children with BLLs of $10 \mu \mathrm{g} /$ $\mathrm{dL}$ or greater were shown to display diagnostic features of attention deficit and hyperactivity disorder [2-5], increased aggression [6], and non-adaptive classroom behavior [7]. Furthermore, intellectual impairments were demonstrated by poor performances on the Wechsler Intelligence Scale for Children (WISC) and the WISC-Revised scale [5,7-9]. Thus $\mathrm{Pb}$ toxicity $(>10 \mu \mathrm{g} / \mathrm{dL})$ serves as a diagnostic differential in children who present with physiological/neurological disturbances such as reduced stature and skeletal growth [10-13], increased seizure frequency [14,15], coma [15], and death [15].

$\mathrm{Pb}$ exposure studies have traditionally used rats and mice for determining the effects of both in vitro and in vivo exposure to $\mathrm{Pb}$. The in vivo studies on rats and mice demonstrate toxic effects of $\mathrm{Pb}$ on the development of motor skills [16], learning and memory [9,17$20]$, and spontaneous and drug-induced locomotor activity [19,21]. Furthermore, mice exposed to a high concentration of $\mathrm{Pb}(100 \mathrm{ppm})$ show a delay in first time attack of an environment intruder compared to control and mice exposed to a lower concentration (50 ppm) [22]. In contrast, $\mathrm{Pb}$ poisoned children demonstrate increased rage and aggression [23,24]. Similar to children, cats with a BLL of $10 \mu \mathrm{g} / \mathrm{dL}$ show decreased predatory attack threshold [25]. This similarity in aggression between children and cats suggests that cats may serve as a more appropriate model for $\mathrm{Pb}$ toxicity in humans than rodents.
Kittens exposed to $\mathrm{Pb}$ develop hyper-spiny dendritic arborizations in the Purkinje cells of the cerebellum [26] and cortical pyramidal cells [27] while $\mathrm{Pb}$-exposed rats show decreased dendritic arborizations of cerebellar Purkinje cells $[26,28,29]$ and alterations in dendritic arborization and spine density of hippocampal pyramidal neurons [3032]. These alterations in hippocampal dendritic spine density in the rat may be associated with an impairment of long-term potentiation in the hippocampus of the rat dentate gyrus following exposure to $\mathrm{Pb}$ [33], which may be responsible for the decrease in learning and memory observed with $\mathrm{Pb}$ exposure [5,7-9]. Although the effect of $\mathrm{Pb}$ exposure on hippocampal neurons of the cat is unknown, it seems reasonable that the observed changes in hippocampal neurons of the rat and the changes observed in the cerebellum [27] and motor cortex [26] of the cat would result in alterations in learning and memory, motor skills and locomotor activity in the cat. The similarity in aggressive behavior between $\mathrm{Pb}$-exposed children and cats [23-25] coupled with the difference in this behavior between children and mice [22], suggests that the cat may be a more appropriate model for human $\mathrm{Pb}$-induced toxicities than the rat. Therefore, the hypothesis examined in this study is that exposure of kittens to $\mathrm{Pb}$ early in life decrease spatial learning, locomotor activity and vestibular reflexes. Testing of this hypothesis

*Corresponding author: Dr. Chad T. Andicochea, Naval Medical Center Camp Lejeune, Department of Emergency Medicine, 100 Brewster Blvd, Camp Lejeune, NC 28547, USA, Tel: 619-876-2481; E-mail: candicochea@gmail.com

Received November 19, 2018; Accepted November 30, 2018; Published December 05, 2018

Citation: Andicochea CT, Ramsey AK, Martin JR (2018) Effect of Exposure to Lead Acetate on Neurobehavior and Learning in the Kitten. J Neurol Neurophysiol 9 : 474. doi:10.4172/2155-9562.1000474

Copyright: $\odot 2018$ Andicochea CT, et al. This is an open-access article distributed under the terms of the Creative Commons Attribution License, which permits unrestricted use, distribution, and reproduction in any medium, provided the original author and source are credited. 
was done using the spatial T-maze, open-field, and jump down tests. The results of this study indicate that $\mathrm{Pb}$ exposure early in life selectively disrupts early spatial learning while having no effect on locomotor activity and the vestibular reflex and that there is a gender difference in the effect of $\mathrm{Pb}$ exposure in cats.

\section{Materials and Methods}

\section{Subjects}

Subjects were thirty-two male and female mongrel kittens born and raised in the animal colony of the A. T. Still University, Kirksville College of Osteopathic Medicine. Kittens were weaned at 6 weeks \pm 2 days and housed with littermates. After birth, each litter was divided equally into experimental and control groups based on stratified randomization. Purina kitten chow and water were provided ad libitum. A normal 12:12 light/dark cycle was used, while room temperature was maintained at $21^{\circ} \mathrm{C} \pm 2^{\circ} \mathrm{C}$. Kittens were tested in a separate experimental room with a similar room temperature of $21^{\circ} \mathrm{C} \pm 2^{\circ} \mathrm{C}$. Exclusion criteria included poor health (as determined by the attending veterinarian), or lack of interest in food reinforcement. Weights of kittens were obtained weekly through the end of the experiment. The Institutional Animal Care and Use Committee of the Kirksville College of Osteopathic Medicine approved the methods described. All protocols are in accordance with the NIH Guide for the Care and Use of Laboratory Animals (1996).

\section{Drugs and dosage}

Starting at Postnatal Day (PND) one until PND seven, the experimental group of kittens were administered $20 \mathrm{mg} / \mathrm{kg} /$ day of lead acetate (Sigma Aldrich, St. Louis, MO) in distilled water while the control group received an equal volume of distilled water via esophageal intubation.

\section{Reversal spatial learning test}

Apparatus: A reversal spatial learning paradigm was used as described earlier by Burgess et al. [34]. This test made use of a T-maze box that measured $1.8 \mathrm{~m}$ long $\times 1.8 \mathrm{~m}$ wide $\times 0.31 \mathrm{~m}$ high. The floor and walls were constructed from $0.6 \mathrm{~cm}$ thick, non-transparentPlexiglas. The T-maze box had a hinged ceiling, also made of $0.6 \mathrm{~cm}$ thick transparent Plexiglas. The ceiling contained an access door at the start point. The T-maze box contained a runway that intersected with a perpendicular corridor with equal length arms $(0.76 \mathrm{~m})$ to the left and right.

Procedure: Pretest-The preferred turning direction of each kitten was assessed by placing the kitten at the start point of the runway while an equal amount of food reward $(\sim 100 \mathrm{~g}$ chicken flavor canned kitten chow) was placed at the end of both the right and left arms of the T-maze. The kittens were allowed to move down the runway and to freely choose one of the two arms (left or right). Once the kitten reached the food reward, the kitten was removed from the arm and the arm chosen was recorded. This test was repeated 10 times per day for five consecutive days (for a total of 50 trials). Total arm choices were tallied to identify an arm preference. The preferred arm (initial choice preference) was determined to be the arm visited $>50 \%$ of the time.

Test-The kittens were given another 10 trails per day for five days of testing in the T-maze. During this testing the food reward was placed in the non-preferred arm (as assessed by initial choice preference), and the number of incorrect arm choices (IAC; nonfood-paired arm) was recorded.

\section{Open-Field behaviour test}

Apparatus: The open-field behavior test used in the present study was adapted from that described by Burgess et al. [34]. Kittens were tested in a $2.5 \mathrm{~m} \times 2.5 \mathrm{~m}$ room with $2 \mathrm{~m}$ high walls. The floor of the open-field chamber was marked with grids of $50 \mathrm{~cm} \times 50 \mathrm{~cm}$. A latched door allowed entrance into the room. A digital camera (JVC; model GRDF43OU) was mounted to the ceiling to record the subject's behavior for later scoring. To control for observer bias, an individual blind to treatment protocol was trained to score behaviors observed in the open-field. Odors in the open-field testing room were controlled by wiping the walls and floor with a multi-purpose cleanser (Clout; Pharmacal Research Laboratories Inc., Naugatuck, CT). Each kitten was placed in the center of the open-field testing room and the next $15 \mathrm{~min}$ of free roaming time was videotaped for later scoring. The observed behaviors were scored as follows: 1) spontaneous locomotion (assessed as the number of lines crossed by all four paws); 2) vocalizations (assessed by the total number of mews); 3) distress vocalizations (assessed as the number of mews lasting longer than $2 \mathrm{sec}$ in duration); 4) wall climb (a score of one was assigned for every five seconds that a subject's front paws reached up a wall); and 5) exploratory behavior (a score of one was assigned for every continuous five seconds that a kitten was observed sniffing the floor).

\section{Free-Fall test}

Apparatus: Grids containing $5 \mathrm{~cm}$ squares were marked on a poster paper, which was placed on the ground. Next to this marked poster paper was a tripod-mounted digital video camera (JVC; model GRDF43OU).

Procedure: Kittens were held right-side-up $91 \mathrm{~cm}$ above the marked poster paper. The digital video camera captured the kitten's free-fall and the initial contact of the paws with the marked poster paper [35]. The number of boxes between the front two paws quantified the distance between the paws on initial contact, while the number of boxes between the paws once the kitten had come to rest quantified the final resting position. The difference in the distance between the initial contact and the final resting position was compared to assess balance retention during free-fall. This procedure was immediately repeated for a total of four tests.

\section{Procedure timeline}

Kittens were placed in the T-maze each day for 5 consecutive days prior to their 8 or 10 weeks birthday as described above. Actual testing was done on 8 and 10 weeks birthdays, which consisted of: 1) open-field test, 2) spatial T-maze test, and 3) free-fall test. Each kitten was placed in a $47 \mathrm{~cm} \times 23 \mathrm{~cm} \times 31 \mathrm{~cm}$ holding cage for five minutes between each test. Subjects were weighed once a week until euthanized.

\section{Statistical analysis}

A 2 (8 and 10- week) $\times 2$ (treatment: lead acetate and distilled water) mixed factorial design was used for data analysis. Dependent variables were scored using discrete numbers based on number of line crosses, vocalizations, distress vocalizations, sniffing, wall climbing, incorrect turning directions in spatial reversal T-maze, and number of boxes between the front paws in the landing base. A 2-way ANOVA for repeated measures was used to determine if a significant difference was present while Student-Newman-Kuels test was utilized to determine which treatment groups were different. Results are reported as the mean \pm SEM., and a $\mathrm{P}<0.05$ was considered statistically significant. To determine if $\mathrm{Pb}$-treatment had a significant effect on gender response 


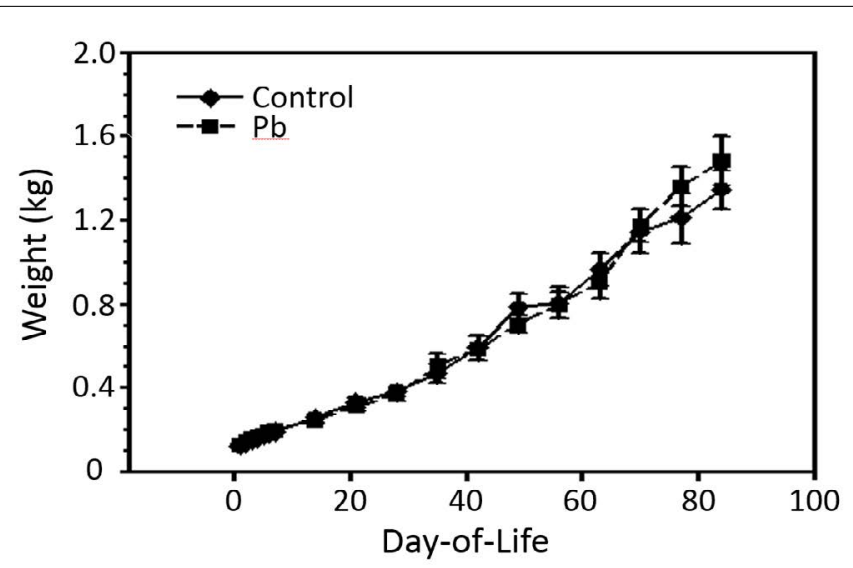

Figure 1: Mean body weights (kg; \pm SEM) of $16 \mathrm{~Pb}$-treated $(\mathbf{m})$ and 16 control $(\bullet)$ kittens as a function of day-of-life. During the first week of life, kittens were weighed daily (PND 1-7), and then weekly until the twelfth week of life.

in the spatial reversal T-maze test a 2-way ANOVA was performed on the following groups: 1) males treated with distilled water, 2) males treated with $\mathrm{PB}, 3$ ) females treated with distilled water and 4) females treated with $\mathrm{Pb}$. Differences between litters could not be tested for due to litters that contained small numbers of kittens. Outliers were tested for significant difference by use of the Q-test.

\section{Results}

\section{Weights}

No differences occurred in the mean weights between $\mathrm{Pb}$-treated and control kittens during development (Figure 1). There was also no significant difference between the mean weights of $\mathrm{Pb}$-treated and control kittens when weights were measured daily during the first week of life. AAA

\section{Spatial reversal learning}

$\mathrm{Pb}$-treated kittens had higher mean total IACs in the spatial T-maze at 8 -weeks of age, but not at 10 weeks of age, when compared to control kittens (Figure 2A). Mean IACs of 8-week old kittens on each day of testing (days 1-5) (where each single day includes 10 trials) is shown in Figure $2 \mathrm{~B}$. Pb-treated 8-week-old kittens made more IACs on all days of testing compared to control kittens. All kittens showed a significantly high number of IACs on the first day of testing compared to days 2-4. IACs of the $\mathrm{Pb}$-treated kittens equaled that of control kittens on day 5. Compared to test day $1, \mathrm{~Pb}$-treated kittens had a $21 \%$ reduction in IACs, while control kittens had a $43 \%$ reduction.

There were no differences between the mean number of IACs between the treatment groups at 10 weeks of age although the number of IACs was higher on day 1 compared to days 2-5 for both groups (Figure 2C). Compared to test day $1, \mathrm{~Pb}$-treated kittens had a $72 \%$ reduction of IACs on day 5, while control kittens had a 52\% reduction of IACs. When testing for differences between males and females, it was found that at 10 weeks female kittens made a greater number of incorrect choices than male kittens (mean IACs for female kittens $=4.45 \pm 0.76 v s .2 .42 \pm$ 0.51 for male kittens; Fx,y=29.31; $\mathrm{p}<0.05$ ). The mean number of IACs made by $\mathrm{Pb}$-treated female kittens at 10 weeks of age was significantly greater than the mean number of IACs made by control female kittens (Figure 3B) while there was no difference between the mean number of IACs made by age and treatment matched male kittens (Figure 3A).
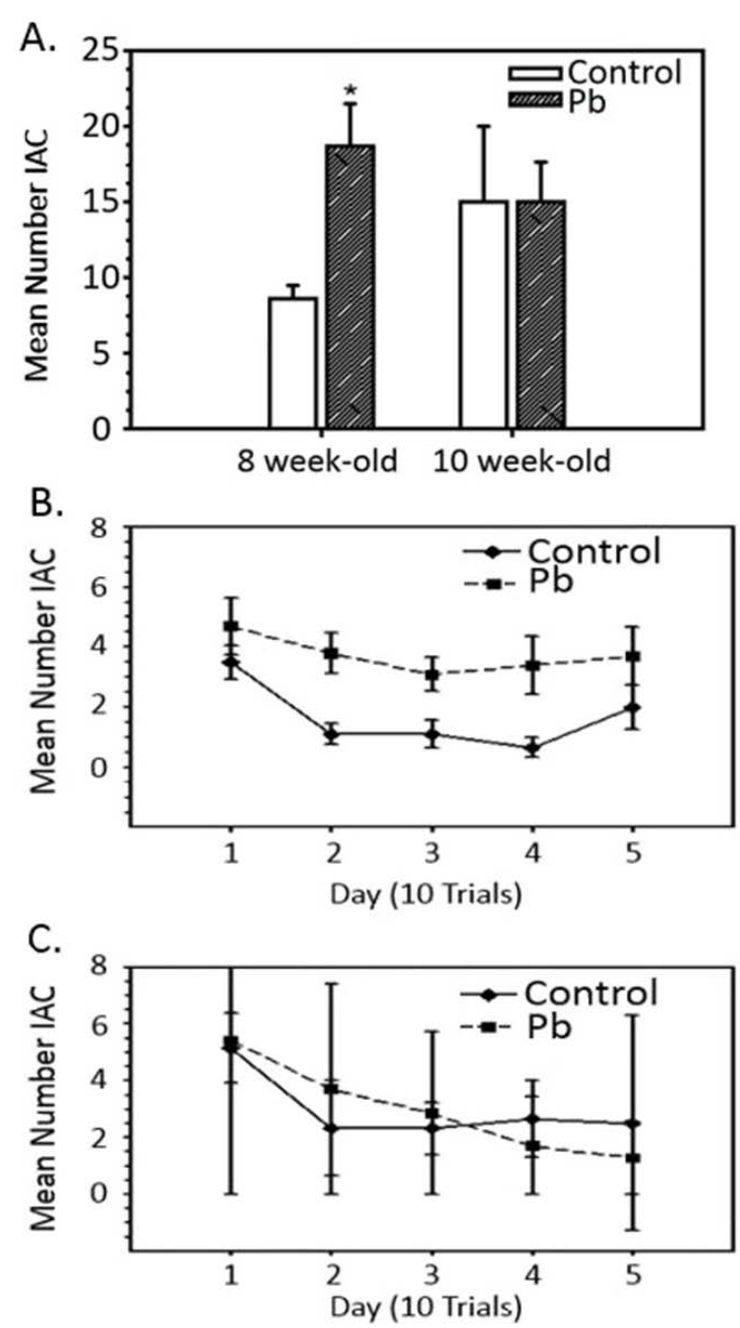

Figure 2: The overall mean number of Incorrect Arm Choices (IAC) made by $\mathrm{Pb}$-treated 8 weeks old kittens in the T-maze was significantly greater from the number made by control kittens (Panel A). However, the number of IAC made during each trial run was not significantly different between the $\mathrm{Pb}$-treated and control kittens although the Pb-treated kittens made more IAC at 8 weeks (Panel B). At 10 weeks of age, the Pb-treated and control kittens made the same number of IAC (Panel C).

Kittens that remained in the T-maze for longer than $300 \mathrm{~s}$ without making an arm choice were given a "Non-Choice" (NC) score for that particular trial. The means of non-choice frequencies were not significantly different $(\mathrm{p}>0.05)$ between the 8 -week old $\mathrm{Pb}$-treated and control kittens $(0.9 \pm 0.5 \mathrm{NCs} v s .4 .00 \pm 1.6 \mathrm{NCs}$, respectively), and in the 10 -week old Pbtreated and control kittens $(0.2 \pm 0.2 v s .0 .0$, respectively).

The amount of time spent in the T-maze during the test and pre-test were not different between the $\mathrm{Pb}$-treated and control groups (Figure 4). All kittens spent more time in the maze on the first day of testing (approximately $110 \mathrm{~s}$ ) which decreased to approximately $20 \mathrm{~s}$ during days 3-5. The Pb-treated group spent more time in the T-maze than the control group on days 1 and 2 . There was no difference in time spent in the T-maze between the two groups at 10 weeks of age, which averaged about $20 \mathrm{sec}$.

\section{Open-Field test}

To quantify spontaneous locomotion, kittens at 8 and 10 weeks of age 


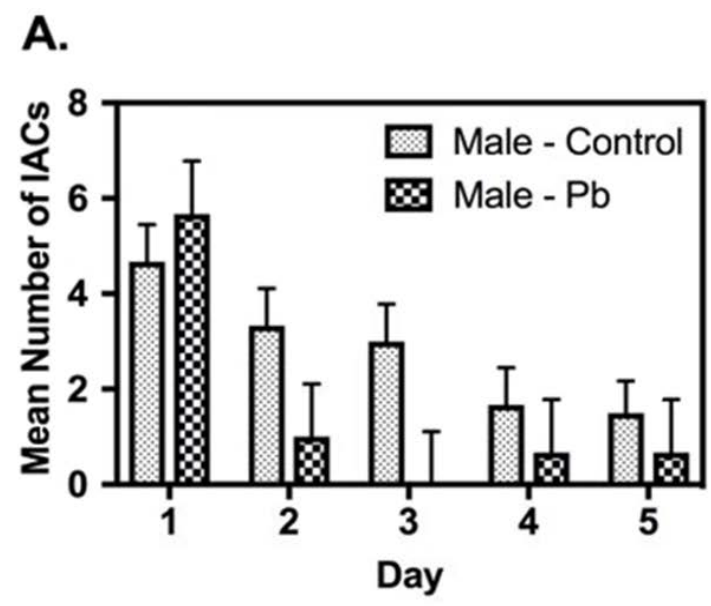

B.

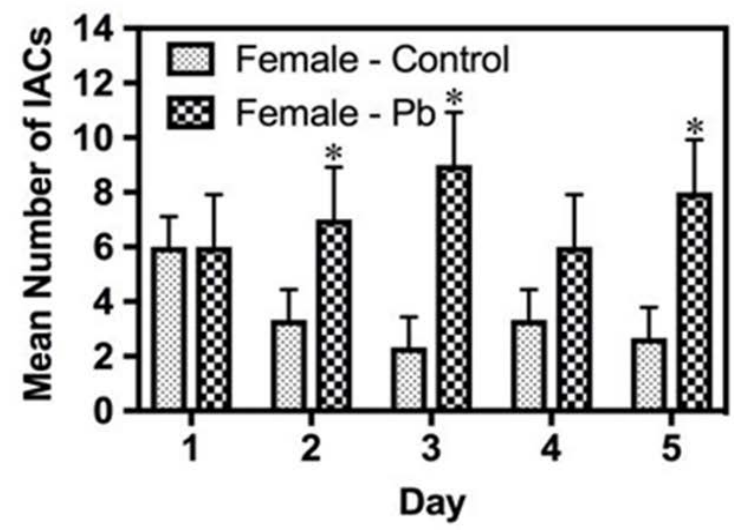

Figure 3: Pb-treated female kittens made a significantly greater number of mean ( \pm SEM) IACs during trials 2, 3 and 5 than control female kittens (Panel $B)$ at 10 weeks. The mean number ( \pm SEM) of Incorrect Arm Choices (IACs) made by $\mathrm{Pb}$-treated male kittens was not different from the number made by control male kittens (Panel A) at 10 weeks of age.

Note: *Significantly different from 10 -week old control kittens $(p<0.05)$.

were placed in the open-field apparatus and the number of line crosses counted over the next 15 mins. The test time of 15 mins was divided into four equal blocks of time of 3.75 mins each for determination of changes in activity over time. Spontaneous locomotor activity did not differ between the $\mathrm{Pb}$-treated and control groups of kittens at 8 or 10 weeks of age. The mean number of line crossings made by the 8 -week old $\mathrm{Pb}$-treated kittens over each consecutive Time Block (TB) was not different from those of the control kittens. The mean number of line crossings for each consecutive TB for the Pb-treated kittens were $119 \pm 38,71 \pm 34,60 \pm 11$, and $52 \pm 39$, respectively, while the line crossings for the control kittens were $92 \pm 29$, $65 \pm 33,46 \pm 29$, and $33 \pm 28$, respectively. Likewise, the mean number of line crosses made by the 10 week old $\mathrm{Pb}$-treated kittens over each consecutive TB was not different from those for the control kittens. The mean number of line crossings for the Pb-treated kittens were $120 \pm 19,89$ $\pm 18,61 \pm 6$, and $52 \pm 7.0$, respectively, while those for the control kittens were $76 \pm 15,83 \pm 19,45 \pm 6$, and $38 \pm 12$, respectively. However, both groups of 8 weeks old kittens had greater locomotor activity during the first TB than during the second, third and fourth TBs, although locomotor activity during the second TB was greater than during the third and fourth TBs (Figure 5). Likewise, both groups of 10 weeks old kittens had greater
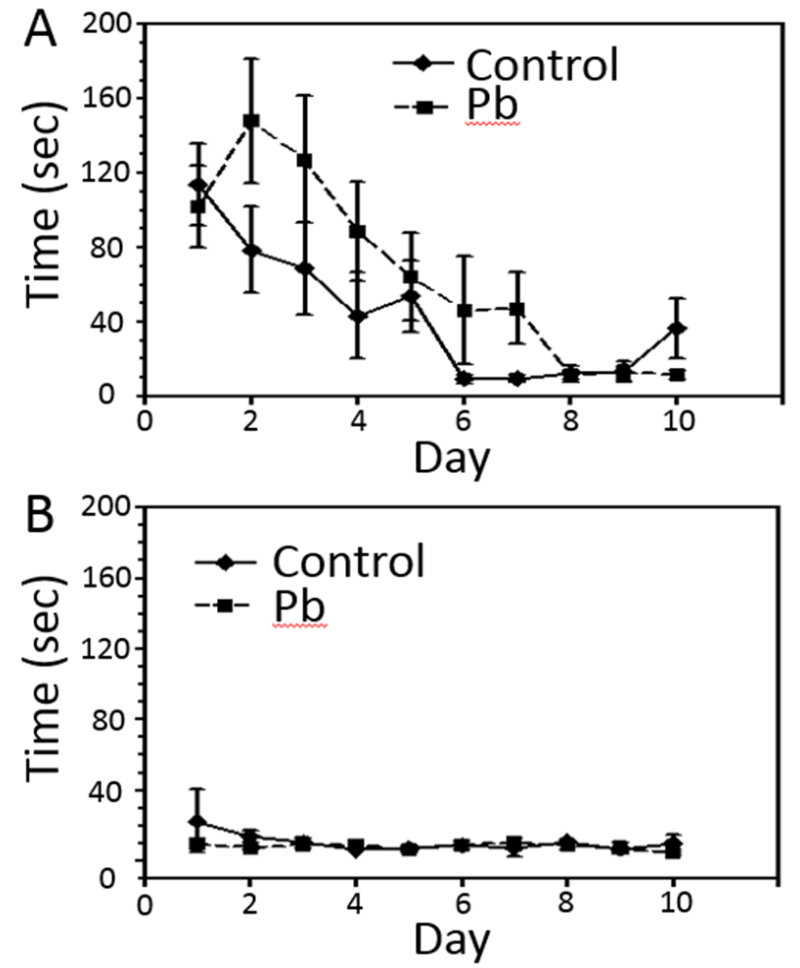

Figure 4: Mean ( \pm SEM) time (sec.) 8 (A) and 10 weeks old (B) Pb-treated ( and control $(\bullet)$ kittens spent in the T-maze box during 5 days of pretest and 5 days of test (10 trials/day).
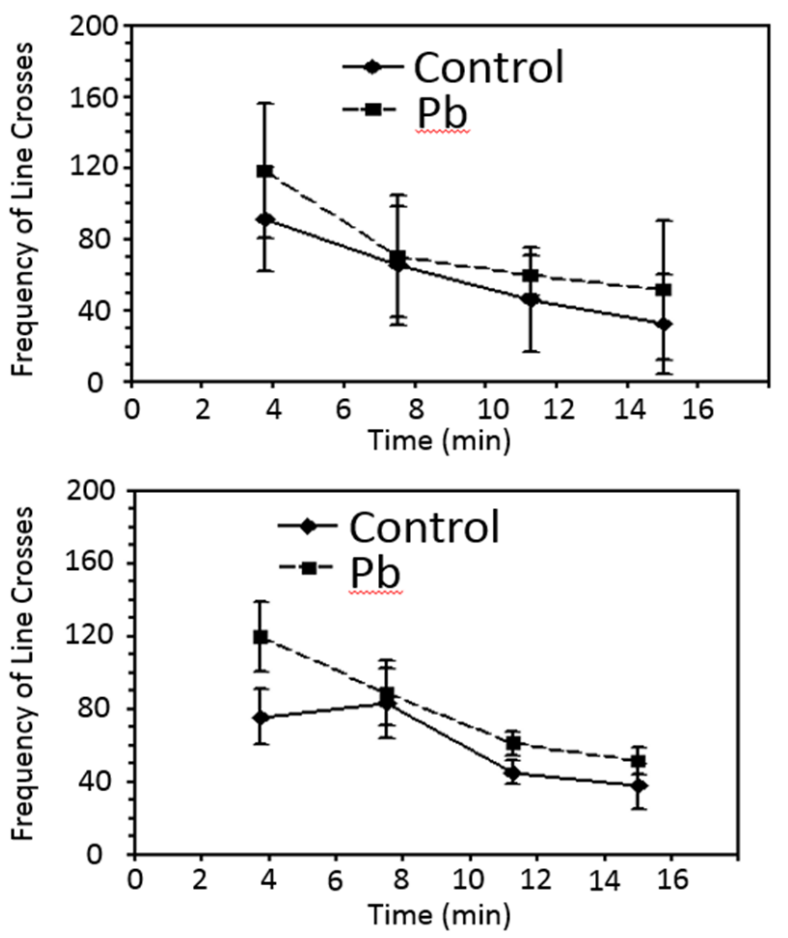

Figure 5: Mean ( \pm SEM) number of line crossing (LCs) made by $8(A)$ and 10 weeks $(\mathrm{B})$ old $\mathrm{Pb}$-treated $(\boldsymbol{\square})$ and control $(\cdot)$ kittens in the open-field test as a function of time where 1 time-block=3.75 mins (total 15 mins). 
locomotor activity during the first TB than during the third and fourth TBs, although locomotor activity was again greater during the second $\mathrm{TB}$ 2 than during the third and fourth TBs.

No differences between $\mathrm{Pb}$-treated and control 8 and 10 weeks old kittens were observed with respect to the behaviors observed during the open-field test. These behaviors included sniffing, wall climbing, mewing, and distress mewing (Figure 6).
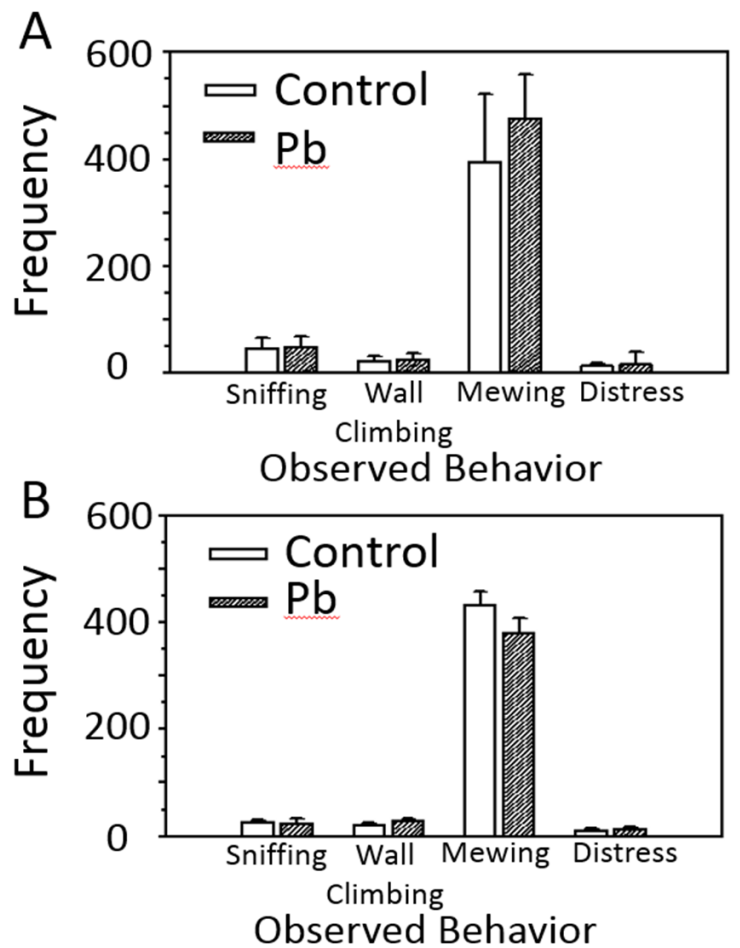

Figure 6: Mean ( \pm SEM) frequencies of Pb-treated and control $8(A)$ and 10 weeks $(B)$ old kittens as a function of behavior (sniffing, wall climb, mew, and distress mew) in the open-field test.

\section{Free-Fall test}

$\mathrm{Pb}$-treated and control kittens were allowed to free- fall from a height of $91 \mathrm{~cm}$ to determine functional ability of the vestibular spinal reflexes. There were no differences between the $\mathrm{Pb}$-treated and control groups at 8 weeks of age with respect to initial contact, final resting position, or difference between the initial and final resting positions (Figures 7 and 8). Likewise, there were no differences between the $\mathrm{Pb}$ treated and control groups at 10 -weeks of age with respect to initial contact, final resting position, or difference between the initial and final resting positions (Figures 7 and 8 ).

\section{Discussion}

$\mathrm{Pb}$-treated rats and mice do not shown elevated aggression [22], which contrasts with clinical observations of $\mathrm{Pb}$-poisoned children $[23,24]$. Pb-induced aggression of cats with BLLs similar to those of $\mathrm{Pb}$-poisoned children suggests that the cat may serve as a better model of human $\mathrm{Pb}$ toxicity than the rat. Results from the present study show that $\mathrm{Pb}$ does not affect weight gain of kittens during development, which is similar to reports of clinical observations of $\mathrm{Pb}$-poisoned children. However, there was a $\mathrm{Pb}$-induced attenuation of spatial learning of the kittens at 8 weeks of age, but not at 10 weeks of age. Pb-treatment did not induce a change in the vestibular spinal reflex, spontaneous locomotor activity or behavior of kittens at 8 or 10 weeks of age.

It is well documented that $\mathrm{Pb}$-poisoned children have impaired learning and intelligence quotients as measured by the WISC and the WISC-R $[5,7,8,36]$. This learning impairment occurs when BLLs are less than $10 \mu \mathrm{g} / \mathrm{dL}$ [4]. Exposure to $\mathrm{Pb}$ in the rat results in decreased hippocampal dendritic arborization and density of spines in the rat [31]. These changes in the hippocampus of the rat may be associated with decreased LTP observed in Pb-exposed rats [33,37], which may explain the decrease in learning and memory found in Pb-exposed rats [5,79]. Although the extent of $\mathrm{Pb}$-induced changes in the cat hippocampus is unknown, the present study shows that $\mathrm{Pb}$-treatment during days 1-7 following birth results in decreased spatial learning of kittens at 8 weeks, but not at 10 weeks, of age. These results suggest that the $\mathrm{Pb}$ induced impairment of learning in the kitten may not be permanent,
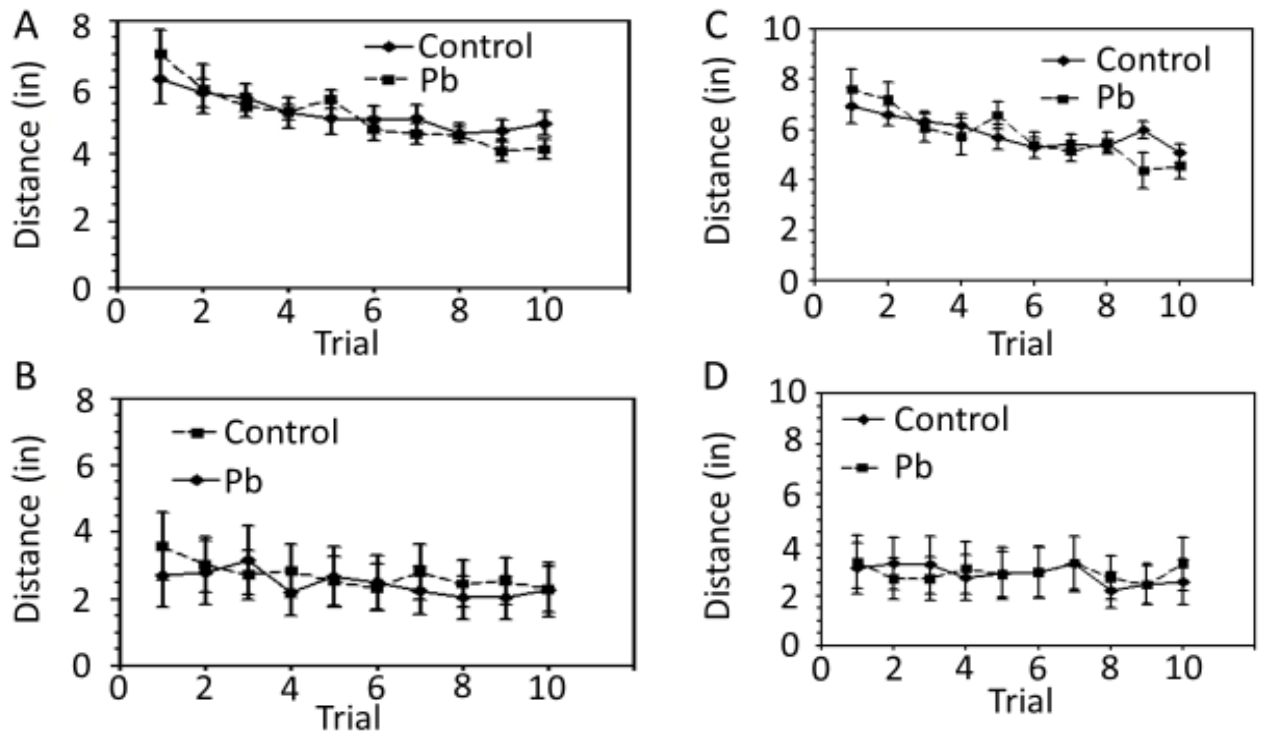

Figure 7: Mean ( \pm SEM) difference of $8(A)$ and 10 weeks $(B)$ old Pb-treated $(\mathbf{})$ and control $(\bullet)$ kitten's initial and rest front paw distance (in.) in the free-fall test. 

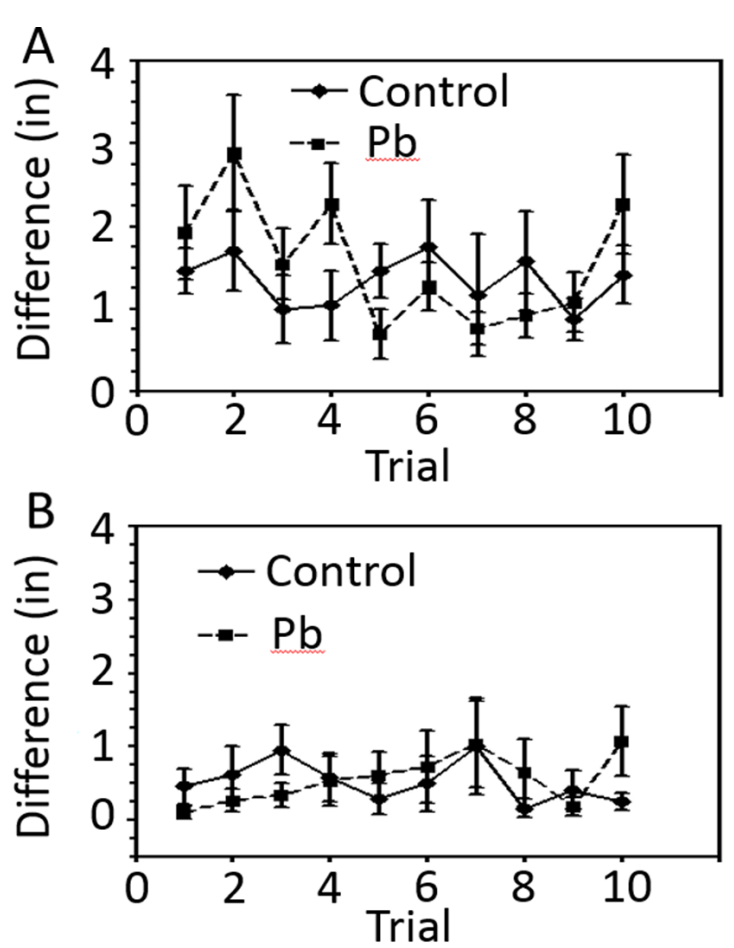

Figure 8: Mean ( \pm SEM) distance (inches (in)) of 8 weeks old (panel A) and 10 weeks old (panel B) Pb-treated $(\bullet)$ and control $(\cdot)$ kitten's front paws upon initial contact with the floor after free-fall descent are shown in the left side of the figure. The mean ( \pm SEM) distance (in.) between the front paws of 8 weeks old (panel C) and 10 weeks old (panel D) Pb-treated $(\mathbf{\bullet})$ and control $(\bullet)$ kittens once rest position was attained following the free-fall descent are shown in the right side of the figure.

but rather $\mathrm{Pb}$-treatment delays spatial learning. It is interesting to note that $\mathrm{Pb}$ toxicity causes a similar delay in children tested for word recognition [38]. When challenged for word recognition, $\mathrm{Pb}$-poisoned children show a significant 4-5 month delay before their performance equals that of children without elevated BLLs.

Children exposed to $\mathrm{Pb}$ are known to display symptoms of attention deficit hyperactivity disorder [16], which are observed when BLLs are $10 \mu \mathrm{g} / \mathrm{dL}$ [9]. Similarly, Pb-exposed rats show increased locomotor activity in the open-field test [21,39-41]. However, these studies used $\mathrm{Pb}$-exposure protocols that elevated BLLs to $21 \mu \mathrm{g} / \mathrm{dL}, 100 \mu \mathrm{g} / \mathrm{dL}$, and even $600 \mu \mathrm{g} / \mathrm{dL}$. Treatment of the kittens in the present study was designed to result in BLLs of $<10 \mu \mathrm{g} / \mathrm{dL}$ as shown in previous studies $[26,27]$. Pb-exposure of kittens in the present study did not alter spontaneous locomotor activity as determined by the number of line crosses in an open-field test. In addition, there were no differences in the other measured behaviors, including mewing, distress mewing, wall climbing, or sniffing, between the $\mathrm{Pb}$-treated and control kittens. A difference in the $\mathrm{Pb}$-exposure protocol might explain the lack of $\mathrm{Pb}$ induced changes on open-field behaviors in the kitten. In the present study, kittens received a low level of $\mathrm{Pb}(20 \mathrm{mg} / \mathrm{kg} /$ day in the form of lead acetate) daily from postnatal days 1 to 7 . As a result, the $\mathrm{Pb}$-treated kittens had several weeks of latency from $\mathrm{Pb}$ treatment until the first test day. This is in contrast to some of the studies that utilized rats in which the rats received continuous exposure to $\mathrm{Pb}$ starting on day one of fetal development until day of testing $[37,40]$. These rats showed increased spontaneous locomotor activity that was associated with elevated BLLs. Thus, continuous exposure of kittens over the eight weeks duration of the present study may have resulted in the development of hyperactivity. This, however, would have been in contrast to the purpose of the present study, which was to determine if early exposure to low levels of $\mathrm{Pb}$ would result in locomotor changes several weeks later.

A morphological study, using the Golgi stain method, identified the development of hyper-spiny dendrites on the Purkinje neurons of the flocculonodular lobe and vermis of the cerebellum of kittens following an identical $\mathrm{Pb}$ treatment paradigm as the one used in the present study [26]. Since these cerebellar regions are involved in the regulation of vestibular reflexes, a change in the $\mathrm{Pb}$-treated kittens from control kittens was expected in the response to testing of these reflexes and motor coordination. In the present study, the free-fall test, which is a simple, reproducible, noninvasive objective test of motor function in cats [42], showed that $\mathrm{Pb}$ treatment had no effect on the distance between the front paws upon initial contact with the floor, or the final resting position of the front paws following the free-fall. Furthermore, the difference between the initial contact with the floor and the final position of the front paws did not differ between control and $\mathrm{Pb}$ treated kittens. The reason for a lack of effect of $\mathrm{Pb}$-treatment on the free-fall test may have been due to a modification of the height used in the present study. An earlier study described the sequence of muscular contractions involved in the vestibular spinal reflex [42]. This study also showed that the vestibular spinal reflex is the most active during the first $160 \mathrm{~m} / \mathrm{sec}$ of the descent, regardless of height. In the present study, the height of the fall was adjusted to $91 \mathrm{~cm}$ in order to prevent harm to the kitten. However, this lower height decreased the time of descent to approximately $61 \mathrm{~m} / \mathrm{sec}[43,44]$. This descent time may be too short a time to allow the vestibular reflex full adjustment of a kitten's position for landing. As a result, the kittens may not have had enough time to adjust and position themselves for their initial landing and subsequent adjustment for full stabilization.

Results of previous studies show that rats and mice exposed to $\mathrm{Pb}$ impairs learning and memory [5,7-9], and suggest that this impairment may be due to altered neurogenesis and morphology [45] and changes in long-term potentiation (LTP) [9,33,44-46]. Since low levels of $\mathrm{Pb}$ exposure in kittens causes the development of hyper-spiny neurons in the motor cortex and cerebellum, while causing the development of hypo-spiny neurons in these same brain regions of the rat, the present study also examined whether this low level of $\mathrm{Pb}$ exposure would cause impairment of learning and memory in the kitten. The present study shows that $\mathrm{Pb}$ exposure $(20 \mathrm{mg} / \mathrm{kg} /$ day for the first seven days of life), which results in BLLs of approximately $0.4 \mu \mathrm{g} / \mathrm{dL}$ as shown in an earlier study [47], causes a transient cognitive impairment, as demonstrated by a decreased performance in the T-maze at 8 weeks of age, but not at 10 weeks of age.

Several reports suggest a gender difference in responses to $\mathrm{Pb}$ treatment early in life. Impairment of spatial memory of $\mathrm{Pb}$-treated male rats may be the result of one or more $\mathrm{Pb}$-induced changes that occur at the molecular level that are greater in the male than the female rat. First, $\mathrm{Pb}$-exposed male rats show a greater increase in hippocampal myoinositol signaling than female rats [48]. Second, male rats treated with $\mathrm{Pb}$ show increased transcription down-regulation factor concentration than female rats [47]. Third, $\mathrm{Pb}$-sensitivity for a NMDA subunit mRNA (NR2A) was also increased in Pb-exposed male rats compared to $\mathrm{Pb}$-exposed female rats [49]. The association of these changes to LTP and thus to spatial learning has not yet been established in the rat although these changes appear to be related. Whether similar types of changes occur in the cat are not yet known, particularly since the female kittens, rather than male kittens, showed impairment in 
spatial learning and memory. Therefore, any suggested changes in the cellular structure of hippocampal neurons and molecular functions in $\mathrm{Pb}$-exposed kittens, and how these changes relate to spatial learning and memory, and how gender differences affect learning memory is purely speculative at this time.

\section{Conclusion}

The results of this study suggest that the kitten is a viable model for studying the central toxic effects of $\mathrm{PB}$ exposure, especially since the cognitive deficits discovered in the present study and the decrease in aggressive threshold reported earlier are similar between humans and cats. However, the return of the impaired cognitive function observed in kittens at 8 weeks to normal in 10 weeks old kittens is presently unknown. Since the cognitive functions of spatial learning and memory are dependent on the hippocampus and the apparent development of LTP, the changes in dendritic neuronal structure of the hippocampus and LTP need to be determined in the kitten following the $\mathrm{Pb}$-treatment paradigm followed in this study. Furthermore, the effect of this $\mathrm{Pb}$-treatment paradigm needs to be determined in both 8 weeks and 10-week old kittens to determine if any changes that occur relate to the cognitive changes observed in the present study. In addition, it should be determined if $\mathrm{Pb}$ treatment causes changes in LTP and whether changes in LTP correlate to the cognitive deficits that occurred in the 8 weeks old kittens, particularly the female kittens. It is possible, however, that the alteration in cognition of the 8 weeks old kitten observed in the present study may not correlate to changes that might be observed in neuronal structure and LTP in future studies. This is particularly true since the previously observed increase in dendritic spines in Purkinje fibers of the cerebellum and cortical pyramidal motor neurons do not correlate with behavioral changes in the vestibular reflex and spontaneous motor activity observed in the present study. In summary, this is the first study to demonstrate impaired cognitive function in $\mathrm{Pb}$-poisoned kittens with a $\mathrm{BLL}$ of $<10$ $\mu \mathrm{g} / \mathrm{dL}$. This finding, coupled with the decrease in aggressive threshold observed in both $\mathrm{Pb}$-poisoned children and kittens suggest that the cat may be a more appropriate animal model for the study of human $\mathrm{Pb}$ poisoning than rodents.

\section{Acknowledgments}

We would like to acknowledge Drs. Tim Geisbuhler and Rene McGovern at A.T. Still University, as well as Dr. Sanders McDougall at California State University, San Bernardino, for their support and advice on this project. We also we acknowledge Roy Turner for the exquisite craftsmanship in the construction of the T-maze box utilized in this study. Funding was graciously provided by the Graduate Program of Kirksville College of Osteopathic Medicine/A.T. Still University of Health Sciences.

\section{References}

1. Filippelli GM, Laidlaw MAS, Latimer JC, Raftis R (2005) Urban lead poisoning and medical geology: An unfinished story. GSA Today 15: 4-11.

2. Bellinger D, Hu H, Titlebaum L, Needleman HL (1994) Attentional correlates of dentin and bone lead levels in adolescents. Arch Environ Health 49: 98-105.

3. Byun YH, Ha M, Kwon HJ, Hong Y-C, Leem JH, et al. (2013) Mobile phone use, blood lead levels, and attention deficit hyperactivity symptoms in children: A longitudinal study. PLoS One 8e59742.

4. Dietrich KN, Ware JH, Salganik M, Radcliffe J, Rogan WJ, et al. (2004) Effect of chelation therapy on the neuropsychological and behavioral development of lead-exposed children after school entry. Pediatrics 114: 19-26.

5. Eppright TD, Sanfacon JA, Horwitz EA (1996) Attention deficit hyperactivity disorder, infantile autism, and elevated blood-lead: A possible relationship. Mo Med 93: 136-138.

6. Sciarillo WG, Alexander G, Farrell KP (1992) Lead exposure and child behaviour. Am J Public Health 82: 1356-1360.
7. Needleman HL, Gunnoe C, Leviton A, Reed R, Peresie H, et al. (1994) Deficits in psychologic and classroom performance of children with elevated dentine lead levels. N Engl J Med 331: 616-617

8. Bellinger DC, Stiles KM, Needleman HL (1992) Low-level lead exposure intelligence and academic achievement: A long-term follow-up study. Pediatrics 90: 855-861.

9. Wang T, Guan RL, Liu MC, Shen XF, Chen JY, et al. (2016) Lead exposure impairs hippocampus related learning and memory by altering synaptic plasticity and morphology during juvenile period. Mol Neurobiol 53: 3740-3752.

10. Ballew C, Khan LK, Kaufmann R, Mokdad A, Miller DT, et al. (1999) Blood lead concentration and children's anthropometric dimensions in the Third National Health and Nutrition Examination Survey. J Pediatr 134: 623-630.

11. Schwartz J, Angle CR, Pirkle JL, Pitcher H (1986) Relationship between childhood blood-lead levels stature. Pediatrics 77: 281-288.

12. Shukla R, Bornschein RL, Dietrich KN, Buncher CR, Berger OG, et al. (1989) Fetal and infant lead exposure effects on growth in stature. Pediatrics 84: 604612.

13. Shukla R, Dietrich KN, Bornschein RL, Berger OG, Hammond PB, et al. (1991) Lead exposure in the early pre-school child: A follow-up report from the Cincinnati lead study. Pediatrics 88: 886-892.

14. Lockitch G, Berry B, Roland E, Wadsworth L, Kaikov Y, et al. (1991) Seizures in a 10-week-old infant: Lead poisoning from an unexpected source. CMAJ 145: $1465-1468$.

15. Meyer XA, Pivertz T, Dignam TA, Homa DM, Schoonover J, et al. (2003) Surveillance for elevated blood lead levels among children--United States, 1997-2001. MMWR Surveill Summ 52: 1-21.

16. Mello CF, Kraemer CK, Filippin A, Morsch VM, Rodrigues ALS, et al. (1998) Effect of lead acetate on neurobehavioral development of rats. Braz J Med Biol Res 31: 943-950.

17. Altmann L, Weinsberg F, Sveinsson K, Lilienthal H, Wiegand H, et al. (1993) Impairment of long-term potentiation and learning following chronic lead exposure. Toxicol Lett 66: 105-112.

18. Gilbert ME, Mack CM, Lasley SM (1996) Chronic developmental lead exposure increases the threshold for long-term potentiation in rat dentate gyrus in vivo. Brain Res 736: 118-124.

19. Moreira EG, Vassilieff I, Vassilieff VS (2001) Developmental lead exposure: Behavioural alterations in the short and long term. Neurotoxicol Teratol 23: 489495.

20. Nihei MK, Guilarte TR (2001) Molecular changes in glutamatergic synapses induced by $\mathrm{Pb} 2+$ : association with deficits of LTP and spatial learning Neurotoxicology 22: 635-643.

21. Miller DK, Nation JR, Jost TE, Schell JB, Bratton GR, et al. (2000) Differentia effects of adult and perinatal lead exposure on morphine-induced locomotor activity in rats. Pharmacol Biochem Behav 67: 281-290.

22. Soeiro TS, Gouvea E, Moreira EG (2007) Behavioral effects induced by subchronic exposure to $\mathrm{Pb}$ and their reversion are concentration and gender dependent. Hum Exp Toxicol 26: 733-739.

23. Chen B, Cai KN, Dietrich J, Radcliffe J, Rogan WJ, et al. (2007) Lead exposure $\mathrm{IQ}$, and behavior in urban 5- to 7-year-olds: Does lead affect behavior only by lowering IQ. Pediatrics 119: e650-e658.

24. Chen D, Schwarz J, Radcliffe J, Rogan WJ (2006) Maternal IQ, child IQ, behavior, and achievement in urban 5-7 year olds. Pediatr Res 59: 471-477.

25. Li W, Han S, Gregg TR, Kemp FW, Davidow AL, et al. (2003) Lead exposure potentiates predatory attack behavior in the cat. Environ Res 92: 197-206.

26. Patrick GW, Anderson WJ (2000) Dendritic alterations of cerebellar Purkinje neurons in postnatally lead-exposed kittens. Dev Neurosci 22: 320-328.

27. Patrick GW, Anderson WJ (2000) Dendritic alterations of cerebellar Purkinje neurons in postnatally lead-exposed kittens. Dev Neurosci 22: 320-328.

28. Lorton D, Anderson WJ (1986) Altered pyramidal cell dendritic development in the motor cortex of lead intoxicated neonatal rats: A Golgi study. Neurobehav Toxicol Teratol 8: 45-50.

29. Lorton D, Anderson WJ (1986) The effects of postnatal lead toxicity on the development of cerebellum in rats. Neurobehav Toxicol Teratol 8: 51-59. 
Citation: Andicochea CT, Ramsey AK, Martin JR (2018) Effect of Exposure to Lead Acetate on Neurobehavior and Learning in the Kitten. J Neurol Neurophysiol 9: 474. doi:10.4172/2155-9562.1000474

30. Alfano DA, Petit TL (1982) Neonatal lead exposure alters the dendritic development of hippocampal dentate granule cells. Exp Neurol 75: 275-288.

31. Hu F, Xu F, Liu ZH, M Ge, Ruan DY, et al. (2014) Developmental lead exposure alters synaptogenesis through inhibiting canonical Wnt pathway in vivo and in vitro. PLoS One 9: 101-894.

32. Kiraly E, Jones DG (1982) Dendritic spine changes in rat hippocampa pyramidal cells after postnatal lead treatment: A Golgi study. Exp Neurol 77 236-239.

33. Ruan DY, Chen JT, Zhao C, Xu YZ, Wang M, et al. (1999) Impairment of longterm potentiation and paired pulse facilitation in rat hippocampal dentate gyrus following developmental lead exposure in vivo. Brain Res 806: 196-201.

34. Burgess JW, Villablanca JR, Levine MS (1986) Recovery of functions after neonatal or adult hemispherectomy in cats. III. Complex functions: Open field exploration, social interactions, maze and holeboard performances. Behav Brain Res 20: 217-230.

35. Walker CJ, Vierck Jr, Ritz LA (1998) Balance of the cat: Role of the tail and effects of sacrocaudal transection. Behav Brain Res 91: 41-47.

36. Wasserman GA, Liu X, Lolacono NJ, Factor-Litvak P, Kline JK, et al. (1997) Lead exposure and intelligence in 7-year-old children: the Yugoslavia Prospective Study. Environ Health Perspect 105: 956-962.

37. Zaiser AE, Miletic $\vee(1997)$ Prenatal and postnatal chronic exposure to low levels of inorganic lead attenuates long-term potentiation in the adult rat hippocampus in vivo. Neurosci Lett 239: 128-130.

38. Fergusson DM, Horwood LJ (1993) The effects of lead levels on the growth of word recognition in middle childhood. Int J Epidemiol 22: 891-897.

39. Frederickson CJ, Frederickson MH (1979) Developmental changes in openfield behavior in the kitten. Dev Psychobiol 12: 623-628.

40. Ma T, Chen HH, Ho IK (1999) Effects of chronic lead $(\mathrm{Pb})$ exposure on neurobehavioral function and dopaminergic neurotransmitter receptors in rats Toxicol Lett 29: 111-121.

41. Wince LC, Donovan CA, Azzaro AJ (1980) Alterations in the biochemica properties of central dopamine synapses following chronic postnatal $\mathrm{PbCO} 3$ exposure. J Pharmacol Expt Therap 214: 642-650.

42. Gruner JA, Young W, DeCrescito V (1984) The vestibulospinal free fall response: a test of descending function in spinal-injured cats. Cent Nerv Syst Trauma 1: 139-159.

43. Verina T, Rohde CA, Guilarte TR (2007) Environmental Pb2+ exposure during early life alters granule cell neurogenesis and morphology in the hippocampus of young adult rats. Neurosci 145: 1037-1047.

44. Gilbert ME, Mack CM, Lasley SM (1999) The influence of developmental period of lead exposure on long-term potentiation in the adult rat dentate gyrus in vivo. Neurotoxicol 20: 57-69.

45. Gilbert ME, Mack CM, Lasley SM (1999) Chronic developmental lead exposure and hippocampal long-term potentiation: biphasic dose-response relationship. Neurotoxicol 20: 71-82

46. Lasley SM, Polan-Curtain J, Armstrong DL (1993) Chronic exposure to environmental levels of lead impairs in vivo induction of long-term potentiation in rat hippocampal dentate. Brain Res 614: 347-351.

47. Schneider JS, Anderson DW, Talsania K, Mettil W, Vadigepalli R, et al. (2012 Effects of developmental lead exposure on the hippocampal transcriptome: influences of sex, developmental period, and lead exposure level. Toxicol Sci 129: $108-125$.

48. Mansouri MT, Naghizadeh B, Lopez-Larrubia P, Cauli O (2012) Genderdependent behavioural impairment and brain metabolites in young adult rats after short term exposure to lead acetate. Toxicol Lett 5: 15-23.

49. Olson L, Bjorklund H, Henschen A, Palmer M, Hoffer B, et al. (1984) Some toxic effects of lead, other metals and antibacterial agents on the nervous system animal experiment models. Acta Neurologica Scandinavica 100: 77-87. 